\title{
Twenty-Year Reflection on the Impact of World Trade Center Exposure on Pulmonary Outcomes in Fire Department of the City of New York (FDNY) Rescue and Recovery Workers
}

\author{
Krystal L. Cleven ${ }^{1}$. C Carla Rosenzvit ${ }^{1} \cdot$ Anna Nolan $^{2,3,4} \cdot$ Rachel Zeig-Owens $^{1,2,5} \cdot$ Sophia Kwon $^{3}$. \\ Michael D. Weiden ${ }^{2,3,4} \cdot$ Molly Skerker $^{1,2}$. Allison Halpren ${ }^{2} \cdot$ David J. Prezant $^{1,2,5}$
}

Received: 8 September 2021 / Accepted: 29 October 2021 / Published online: 11 November 2021

(c) The Author(s), under exclusive licence to Springer Science+Business Media, LLC, part of Springer Nature 2021

\begin{abstract}
After the terrorist attacks on September 11, 2001 (9/11), many rescue/recovery workers developed respiratory symptoms and pulmonary diseases due to their extensive World Trade Center (WTC) dust cloud exposure. Nearly all Fire Department of the City of New York (FDNY) workers were present within $48 \mathrm{~h}$ of $9 / 11$ and for the next several months. Since the FDNY had a well-established occupational health service for its firefighters and Emergency Medical Services workers prior to 9/11, the FDNY was able to immediately start a rigorous monitoring and treatment program for its WTC-exposed workers. As a result, respiratory symptoms and diseases were identified soon after $9 / 11$. This focused review summarizes the WTC-related respiratory diseases that developed in the FDNY cohort after 9/11, including WTC cough syndrome, obstructive airways disease, accelerated lung function decline, airway hyperreactivity, sarcoidosis, and obstructive sleep apnea. Additionally, an extensive array of biomarkers has been identified as associated with WTC-related respiratory disease. Future research efforts will not only focus on further phenotyping/treating WTC-related respiratory disease but also on additional diseases associated with WTC exposure, especially those that take decades to develop, such as cardiovascular disease, cancer, and interstitial lung disease.
\end{abstract}

Keywords World trade center $\cdot 9 / 11 \cdot$ Obstructive airways disease $\cdot$ Lung injury $\cdot$ Occupational exposure

\section{Introduction}

In the 20 years since September 11, 2001 (9/11), many health problems have burdened the lives of rescue/recovery workers as well as survivors of this tragedy. Over 400,000 people were exposed to the toxins, physical, and emotional trauma in the days and months following the attacks [1]. The Fire Department of the City of New York (FDNY) workforce was nearly all present within the first $48 \mathrm{~h}$ after $9 / 11$ and then for several months providing rescue and recovery efforts. They were heavily exposed to World Trade Center (WTC) dust containing inorganic species, metals, pesticides, asbestos, polycyclic aromatic hydrocarbons, and other hydrocarbons $[2,3]$. The WTC dust consisted of highly alkaline particulate matter of sizes greater than $10 \mu \mathrm{m}$ [2], which typically undergo nasopharyngeal filtration [4]. However, the overwhelming extent of dust exposure coupled with the increased respiratory demand during rescue and recovery work resulted in both upper and lower airways being 
heavily impacted [5]. As a result, medical monitoring of those exposed began shortly after 9/11 [6].

In 2011, the James Zadroga 9/11 Health and Compensation Act of 2010 (Zadroga Act) [7] was signed into law, creating the World Trade Center Health Program (WTCHP), thereby unifying medical monitoring and treatment of WTCrelated health conditions into a federally funded program. Under the WTCHP, in addition to the FDNY program covering firefighters and Emergency Medical Services (EMS) providers, there is also the General Responder WTC Health Program following non-FDNY rescue/recovery workers [8], the Bellevue WTC Environmental Health Center (WTC EHC) covering neighborhood residents, local workers, and clean-up workers/volunteers [9], and the Pentagon/Shanksville Responder cohort which includes rescue/recovery workers at the Pentagon and plane crash site in Shanksville Pennsylvania [10]. The WTC Health Registry is an additional cohort of over 70,000 people who were near the WTC which tracks the health outcomes of 9/11 exposure with a series of questionnaires [10]. Unlike the other cohorts, it does not provide 9/11-related treatment. Because the FDNY had a well-established occupational health service for its firefighters and EMS providers prior to 9/11, the FDNY was able to immediately start a rigorous monitoring and treatment program for its nearly 16,000 WTC-exposed rescue/ recovery workers [5]. These annual exams include health questionnaires, laboratory data, audiograms, spirometry, and chest radiographs. This cohort has had the unique strength of being able to compare the occurrence of new findings to their pre-9/11 prevalence, strengthening any conclusions as to whether conditions were associated with WTC exposure.

The health impacts of 9/11 include not only aerodigestive diseases such as chronic rhinosinusitis, gastroesophageal reflux disease (GERD), lung diseases (obstructive and interstitial), and sleep apnea but also many cancers and mental health conditions, such as depression, anxiety, and post-traumatic stress disorder (PTSD) [5, 11-22]. Currently over 65,000 [23] individuals have qualifying WTC-related diagnoses, over 11,000 of whom are retired or active FDNY workers. This focused review provides a summary of pulmonary-related issues in the 20 years since 9/11/2001 that have impacted WTC-exposed FDNY responders.

\section{WTC-Related Respiratory Conditions}

\section{WTC Cough Syndrome}

In the days and months after $9 / 11$, the most common selfreported symptom among FDNY workers was new onset cough and sore/hoarse throat [24]. What soon became known as "WTC cough syndrome" was defined as persistent cough that developed after exposure to the site and was accompanied by respiratory symptoms severe enough to require medical leave for at least 4 weeks [24-26]. Nearly all FDNY first responders who developed WTC cough syndrome were present at the WTC site within $48 \mathrm{~h}$ of $9 / 11$, most of whom were considered highly exposed as they were present on the morning of $9 / 11$ and exposed to the WTC dust cloud [26]. WTC cough syndrome has been found to be associated with obstructive airways disease, airway hyperreactivity, radiographic evidence of airway inflammation (i.e., air trapping and bronchial wall thickening on chest CT imaging), GERD, chronic rhinosinusitis, and PTSD [18, 24, 26]

\section{Airway Hyperreactivity}

Pulmonary function testing conducted immediately after 9/11 identified airway obstruction and hyperreactivity associated with WTC exposure [27]. Similar to findings in the non-FDNY volunteer/responder [28-30] and survivor cohorts $[9,31]$, this relationship was strongly associated with exposure intensity in FDNY rescue/recovery workers [27]. Even after 6 months, FDNY workers most highly exposed (arrived on the morning of 9/11) were over six times more likely to have airway hyperreactivity based on methacholine challenge testing (MCT) than those with moderate exposure or no exposure in the first 2 weeks after $9 / 11$ [32]. These findings were independent of baseline airway obstruction and smoking status and in follow-up studies were found to have persisted even 12 months after 9/11 [32, 33]. Unlike the typical expected decrease in bronchial hyperreactivity after removal of noxious stimuli in traditional occupational asthma [34], Aldrich et al. found persistence of airway hyperreactivity in FDNY rescue/recovery workers 10 to 12 years after $9 / 11$ exposure [35].

\section{Decline in FEV}

Although the majority of FDNY rescue workers continued to have normal forced expiratory volume in one second $\left(\mathrm{FEV}_{1}\right)$ post-9/11, two clinically relevant patterns of loss of $\mathrm{FEV}_{1}$ have been observed. Aldrich et al. reported a significant mean decrease in $\mathrm{FEV}_{1}$ in the first year after 9/11 on annual spirometry of $439 \mathrm{~mL}$ in firefighters and $267 \mathrm{~mL}$ in EMS workers who never smoked. Interestingly, despite normal lung function prior to $9 / 11$, little to no recovery in $\mathrm{FEV}_{1}$ to pre-9/11 function was observed during years of followup [36, 37]. Additionally, after several years of medical monitoring it became clear that although some had partial improvement in lung function post-9/11, there was a subset of FDNY workers who continued to have persistent accelerated $\mathrm{FEV}_{1}$ decline, while others had their expected agerelated decline (Fig. 1) [26, 36, 38, 39]. It was also demonstrated that bronchial hyperreactivity along with respiratory symptoms such as cough, chest tightness, and shortness of 
Fig. 1 FEV $_{1}$ decline after WTC exposure in FDNY workers

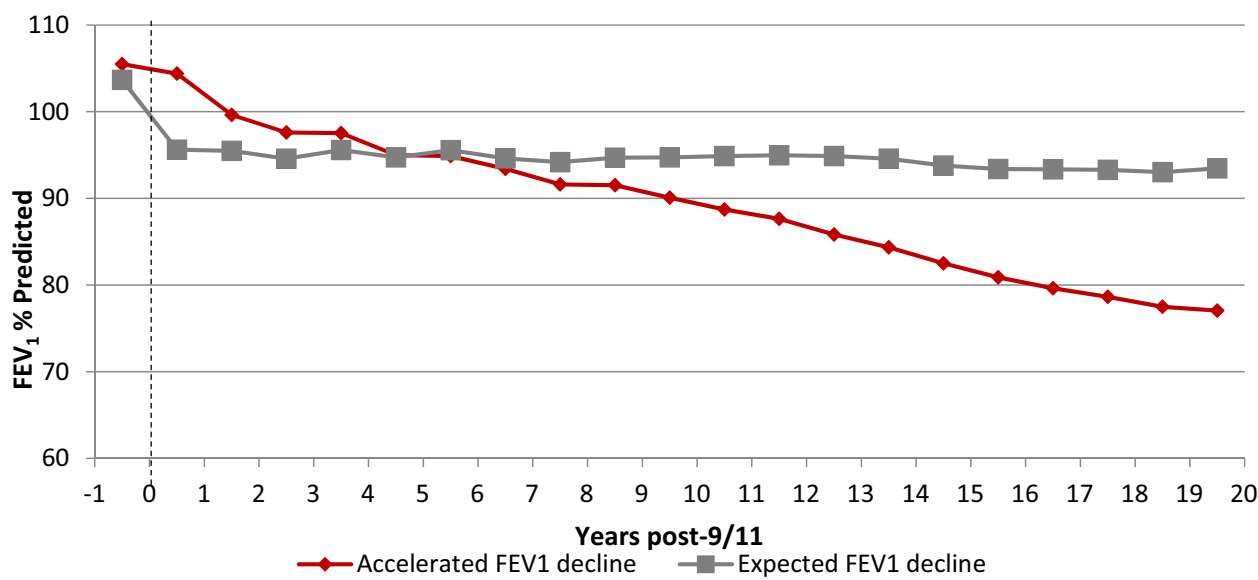

breath were more prevalent in those with a decline in $\mathrm{FEV}_{1}$ post-9/11 [35]. Soon the term "WTC-lung injury" (WTC$\mathrm{LI}$ ) was defined as newly decreased $\mathrm{FEV}_{1}$ below the lower limit of normal [40].

\section{WTC Metabolic and Inflammatory Biomarkers}

Multiple studies have focused on understanding the underlying metabolic and inflammatory pathways associated with post-9/11 decline in lung function and obstructive airways disease (Table 1). Studies of serum biomarkers within 6-month post-9/11 from a sample of 801 FDNY firefighters were conducted to identify biomarkers related

Table 1 Overview of biomarkers and representative references

\begin{tabular}{lll}
\hline Effect & Class & Variable \\
\hline Risk of WTC-LI & Inflammation & GM-CSF; MDC [41] \\
& Matrix metalloproteinases & MMP-1 [42, 44] \\
& Immunoglobulins & IgE [43] \\
& Metabolic/clinical characteristics & Dyslipidemia, obesity, insulin resistance, elevated \\
& Lipid/RAGE axis & heart rate, elevated leptin [48-51] \\
& Apolipoproteins & LPA; sRAGE [52, 53] \\
& Leukocytes & ApoAI, ApoAII [40, 52] \\
& Serpins & a'Neutrophils; ${ }^{\text {EEosinophils [94] }}$ \\
& Interleukins & a'Low alpha-1 antitrypsin; decreased PEDF [38, 56] \\
Cardiovascular markers & a'IL- 4, -5, and -13 [95] \\
Protective of WTC-LI & CRP, MIP-4 [40, 44] \\
& Protein metalloproteinases & MMP-3 and -12 [44] \\
Post-WTC FEV & Necovery & GRO and MCP-1 [42, 56] \\
& Macrophage activity marker & Amylin [48] \\
WTC-AHR & Matrix metalloproteinases & Chitotriosidase [43] \\
& Matrix metalloproteinase inhibitor & MMP-2 [42] \\
& Metabolic syndrome characteristics & TIMP-1 [42] \\
\end{tabular}

$A H R$ airway hyperreactivity, $A P O$ apolipoprotein, $C R P$ C-reactive protein, $G M-C S F$ granulocyte-macrophage colony-stimulating factor, $G R O$ growth-regulated oncogene protein, $H D L$ high-density lipoprotein, $H T N$ hypertension, $I g$ immunoglobulin, $I L$ interleukin, $L P A$ lysophosphatidic acid, $M C P$ monocyte chemoattractant protein, $M D C$ macrophage-derived chemokine, $M I P$ macrophage inhibitory protein, $M M P$ matrix metalloproteinase, $P E D F$ pigment epithelium-derived factor, $s R A G E$ soluble receptor for advanced glycation end-products, TIMP tissue inhibitors of metalloproteinases, WTC-LI world trade center lung injury

${ }^{a}$ Also associated with accelerated $\mathrm{FEV}_{1}$ decline 
to risk or protection against WTC-LI [41-44]. Granulocyte-macrophage colony-stimulating factor (GM-CSF) and macrophage-derived chemokine (MDC) increased the risk of WTC-LI by 2.5 -fold and 2.95 -fold, respectively [41]. Elevations of matrix metalloproteinase-1 (MMP-1) [42] and immunoglobulin E (IgE) [43] were also found to be risk factors for WTC-LI. Using a definition of accelerated $\mathrm{FEV}_{1}$ decline ( $\geq 64 \mathrm{~mL} /$ year), Weiden et al. found that interleukin-4, -5 , and -13 were associated with greater FEV decline when controlling for several important confounders, such as WTC exposure intensity and smoking status [45]. Additionally, others found lower levels of serum alpha-1 antitrypsin (AAT) and higher serum levels of eosinophils and neutrophils were associated with accelerated $\mathrm{FEV}_{1}$ decline after 9/11 [38, 39]. Alternatively, the protective qualities of MMP- 3 and MMP-12 were confirmed in a nested case-control study by Kwon et al. which showed that each $\log$ increase of MMP-3 and MMP-12 reduced the odds of developing WTC-LI by $73 \%$ and $54 \%$, respectively [44]. Additionally, a subset of FDNY workers with elevated chitotriosidase levels, an enzyme vital in the innate host defense against bacterial and fungal infections [46], showed recovery of their forced vital capacity (FVC) and $\mathrm{FEV}_{1}$ to their pre-9/11 levels on average 32 months after the attack [43]. Finally, Nolan et al. found that the odds of regaining lung function after WTC exposure were higher in those with higher levels of MMP-2 and tissue inhibitors of matrix metalloproteinase (TIMP-1) [42].

Several studies have explored the relationship between lung function post-9/11 and systemic inflammatory biomarkers found in patients with metabolic syndrome or other cardiovascular abnormalities. A case-control study of FDNY workers found an association between dyslipidemia, elevated heart rate and elevated leptin levels, a biomarker for metabolic syndrome [47], and the development of WTC-LI after adjusting for confounders, such as body mass index (BMI). Meanwhile, amylin was found to be protective for WTC-LI [48]. Furthermore, studies have evaluated the relationship between metabolic syndrome risk factors (i.e., abdominal obesity, insulin resistance, hypertriglyceridemia, low HDL levels, and hypertension) near the time of WTC exposure and new WTC-LI or airway hyperreactivity several years later [49-51]. Kwon et al. reported as much as a $69 \%$ increased risk of airway hyperreactivity for those with $\geq 3$ metabolic syndrome risk factors, which was independent of other known risk factors, such as smoking status and WTC exposure intensity [49]. They later reported that having metabolic syndrome increased risk of developing WTC-LI by $56 \%$ [50]. The odds of developing WTC-LI years after WTC exposure have also been shown to increase in those with elevations within 6-month post-9/11 of cardiovascular serum biomarkers, such as apolipoprotein A-I (ApoAI) and ApoAII, C-reactive protein (CRP) levels, soluble Receptor for Advanced Glycation End-Products (sRAGE), and lysophosphatidic acid (LPA) [40, 41, 48, 50, 52, 53].

Additionally, high-throughput metabolomics have facilitated the assessment of the metabolome of those with WTCLI and bioactive classes of lipid and amino acid metabolites have been identified [54, 55]. A multivariate predictive model of firefighters with WTC-LI was developed by integrating the metabolome with clinical, cytokine, chemokine, and environmental characteristics to improve early identification of disease [56]. Increased growth-regulated oncogene protein (GRO), monocyte chemoattractant protein-1 (MCP1 ), and decreased macrophage-derived chemokine (MDC) were protective of WTC-LI. Pigment epithelium-derived factor (PEDF) was found to be a novel predictive biomarker of the negative health effects of particulate matter exposure and decreased levels along with macrophage inflammatory protein-4 (MIP-4), and increased ApoAII were associated with WTC-LI [56]. Many of these risk factors for metabolic syndrome and for cardiovascular disease are modifiable which could aid in reducing pulmonary dysfunction not only in WTC cohorts but also in the general population.

\section{WTC-Related Sarcoidosis}

Sarcoidosis is a systemic granulomatous disease that develops after a genetically primed abnormal immune response to an antigen exposure or inflammatory trigger [57]. Thus, soon after the massive antigen exposure that was $9 / 11$, annual radiographs in FDNY workers demonstrated an increase in intrathoracic adenopathy and later tissue samples confirmed an increased incidence of sarcoidosis (intra- and extrathoracic) above that observed in non-WTC cohorts of similar sex, age, and race [58,59]. The average annual incidence increased initially from $15 / 100,000$ in the 15 years prior to $9 / 11$ to $85 / 100,000$ in the year after $9 / 11$ and then stabilized at 25/100,000 after 2002. Similar findings were reported in both survivor and non-FDNY rescue/recovery cohorts [60-62]. Unlike pre-9/11 sarcoidosis cases within the FDNY cohort, those with newly diagnosed sarcoidosis post-9/11 were more likely to have new asthma symptoms and airway hyperreactivity [59]. Hena et al. extensively characterized the clinical course of post-9/11 sarcoidosis in the FDNY cohort both at the time of diagnosis and again in 2015 (Fig. 2) [63]. All had pulmonary involvement at diagnosis and the majority had radiologic findings consistent with mostly stage I and II disease [63, 64]. Nearly half had resolution of intrathoracic involvement at the time of follow-up 8 to 10 years later. Pulmonary function metrics were within normal limits for nearly all, changed little over time, and were not related to radiographic disease patterns [64]. Alternatively, extrapulmonary involvement increased from diagnosis to the time of follow-up with cardiac and 


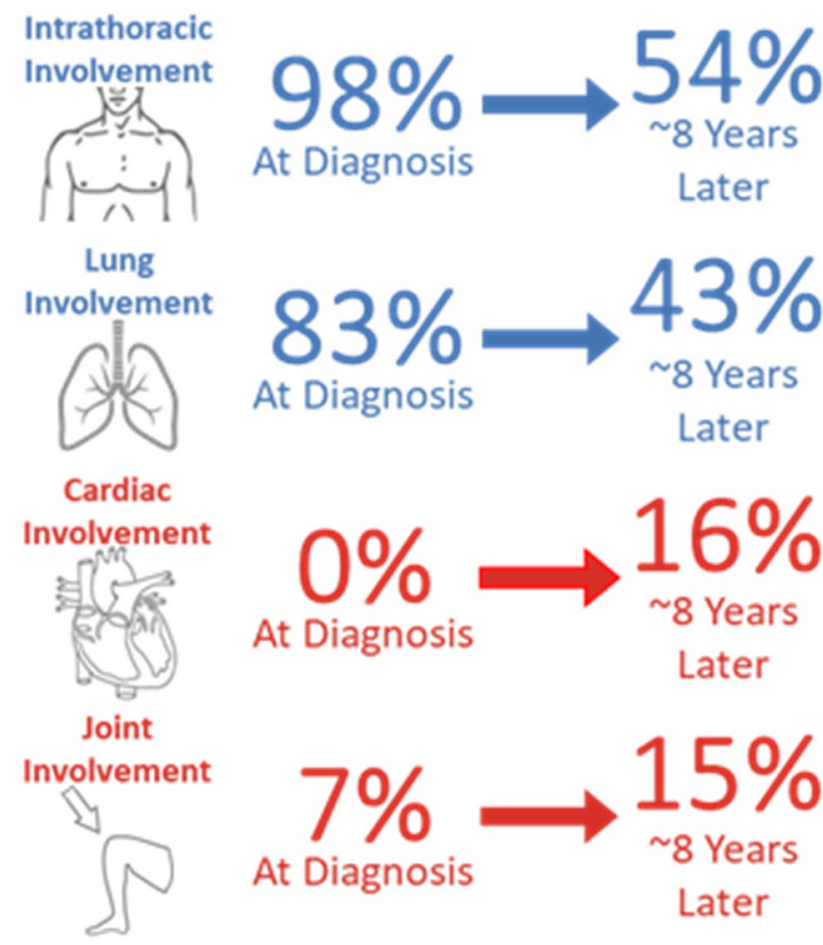

Fig. 2 Pulmonary and extrapulmonary organ involvement of sarcoidosis at baseline and follow-up

bone/joint involvement being the most prevalent. It remains unclear whether the increased prevalence of cardiac sarcoid was due to WTC exposure alone or whether some of the association was due to increased surveillance. An argument in favor of surveillance bias is that everyone enrolled in the study had extensive screening for cardiac sarcoidosis, including cardiac magnetic resonance imaging (MRI). Cardiac MRI was far more sensitive than electrocardiogram and/ or echocardiograms, which missed nearly half of those with cardiac sarcoidosis [63]. Regardless of etiology and because cardiac sarcoidosis can be fatal, their findings suggest a greater need for potentially life-saving-advanced cardiac screening in asymptomatic patients, especially those with public safety responsibilities. Additionally, several unique genetic variants were identified in those with post-9/11 sarcoidosis in a nested case-control study matching based on degree of WTC exposure, age, sex, and race [65]. Seventeen allele variants of HLA and non-HLA genes were found to be associated with sarcoidosis in the FDNY cohort, all of which were in chromosomes 1 and 6 . Although many of the singlenucleotide polymorphisms (SNPs) had never been reported before, one consistent finding with prior studies was an association between the SNP rs20417 which previously was shown to be associated with sarcoidosis in a northern European, mostly Caucasian cohort [66]. Although the sample size used for the FDNY sarcoidosis cohort was too small to identify specific alleles associated with extrapulmonary sarcoidosis phenotypes, there were several novel genetic variants found to be associated with extrapulmonary sarcoidosis generally [65]. Larger genetic studies of other WTC cohorts may help further understand these genetic relationships.

\section{WTC-Associated Obstructive Sleep Apnea (OSA)}

Although obstructive airways disease and hyperreactivity were the most common new pulmonary diseases reported in FDNY workers post-9/11, obstructive sleep apnea was also found to be associated with WTC exposure in survivor, non-FDNY rescue/recovery workers, and FDNY workers [14, 15, 67]. In 2011 Webber et al. [14] demonstrated that of 11,701 FDNY workers studied who were WTC exposed within 2 weeks of 9/11, 44\% were considered at high risk for OSA based on a modified Berlin Questionnaire [68]. Interestingly, of those considered high risk, only $13.9 \%$ had a physician diagnosis of OSA. This study, like other WTC-related airway conditions, demonstrated a WTC exposure dose-response relationship in that those most highly exposed had the highest odds of being at risk for OSA. Also similar to other WTC-related airways diseases summarized above, they found an independent relationship between OSA and other WTC syndromes, such as GERD, chronic rhinosinusitis, and PTSD [14]. A follow-up study by Glaser et al. evaluated those who screened positive on the Berlin screener for OSA and had polysomnography testing; they found that $81 \%$ of the study participants were diagnosed with OSA. They also demonstrated that those with the highest level of WTC exposure were more likely to be diagnosed with severe OSA with an OR 1.91 (1.15-3.17), which was independent of BMI [15]. These studies suggest a relationship between OSA, a likely source of chronic systemic inflammation [69], and WTC exposure. Thus, there should be a low threshold to evaluate those with high WTC exposure and other WTC syndromes, such as GERD, PTSD, and chronic rhinosinusitis for OSA.

\section{Unique Treatment Approaches to WTC-Related Disease}

Given the high prevalence of bronchial hyperreactivity, obstructive airways disease, and symptoms, such as cough, wheezing, and shortness of breath, the most commonly prescribed treatments have been inhaled corticosteroids (ICS) with or without long-acting beta agonists (LABA). Other treatments have included systemic oral corticosteroids, ipratropium inhalation, and/or leukotriene receptor antagonist. Given an equal or even higher prevalence of GERD and/ or chronic rhinosinusitis, treatment often included proton 
pump inhibitors, acid-free diets, nasal saline rinses, and nasal sprays (antihistamines, decongestants, corticosteroids, and/or ipratropium) [70-72]. Initial studies noted that the use of corticosteroids had no effect on airway reactivity but did slow the rate of $\mathrm{FEV}_{1}$ decline [35]. Later in a study evaluating 8,530 FDNY firefighters, 19\% were prescribed ICS/LABA in the 16-year period after 9/11. When dyspnea was measured using the modified Medical Research Council (mMRC) dyspnea scale score, those without improvement in their dyspnea score after the initiation of ICS/LABA were more likely to have delayed treatment-increased time between $9 / 11$ and treatment initiation. Those with improvement in their dyspnea were initially the most symptomatic and, perhaps because of that, were started the earliest on treatment after 9/11 [73]. Further study of this cohort found that those treated the earliest with ICS/LABA (prior to the median date of treatment initiation in the group) had the greatest improvement in $\mathrm{FEV}_{1}$ slope post-treatment [74]. Although it is difficult to account for treatment bias, these studies suggest that delays in treatment may contribute to worsening lung injury after WTC exposure [73, 74].

Additionally, FDNY firefighters with WTC-related sarcoid arthritis, one of the most common extrapulmonary manifestations, were treated with disease-modifying antirheumatic drugs (DMARDs) for steroid refractory disease, as is standard for a stepwise escalation of therapy [75, 76]. However, eight of the eleven treated with hydroxychloroquine did not experience adequate disease control of their articular symptoms, while three experienced either partial or complete response. After a 3-month trial of hydroxychloroquine, they were given methotrexate but again suboptimal symptom control was achieved. Finally, anti-tumor necrosis factor alpha (anti-TNF $\alpha$ ) agents were initiated with over a $70 \%$ improvement in symptoms. Cardiac sarcoidosis has been similarly treated with stepwise escalation from corticosteroids to methotrexate to anti-TNF $\alpha$ agents. Unlike non-WTC-related sarcoidosis, most with this unique WTC exposure required a higher escalation of therapy to achieve control.

Finally, the therapeutic potential of attenuating metabolic syndrome risk in those with WTC-LI is being explored. To investigate the hypothesis that a low-calorie Mediterraneantype diet will reduce the primary clinical endpoint of body mass index (BMI) and will positively impact the secondary endpoints, such as $\mathrm{FEV}_{1}$, the Food Intake REstriction for Health OUtcome Support and Education (FIREHOUSE) trial was developed [77-80]. This collaborative randomized clinical trial utilizes self-monitored diet, physical activity recommendations, and cloud-based self-monitoring with Social Cognitive Theory (SCT)-based behavioral counseling delivered via video sessions [81] to WTC-exposed firefighters with WTC-LI. The goal of this study is to evaluate if these novel technology-supported Mediterranean diet and lifestyle modifications can further improve the treatment of WTC pulmonary disease. The treatment needs of this cohort

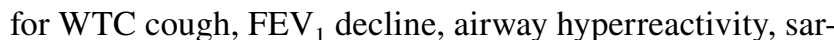
coidosis, and WTC-LI underscore the importance of close longitudinal follow-up so that individualized treatment can be initiated after a unique exposure, such as WTC.

\section{Future Directions in FDNY WTC Research}

Cohort studies after non-WTC exposures such as tobacco or asbestos raise serious concerns that twenty years after 9/11 incidence rates for interstitial lung diseases and lung cancer may rise to levels not seen in the general population. The WTC Health Registry has reported an increased incidence rate for self-reported interstitial lung disease in those with the highest WTC exposure history [82]. FDNY is currently involved in a CT imaging study to determine whether radiologic-confirmed interstitial disease is increased compared to the general population. As for lung cancer, three WTC cohorts (FDNY, General Responder Cohort, and WTC Health Registry) have reported lower than expected rates when compared to the general population [16, 83-86]. This is likely due to lower rates of tobacco smoking and the fact that solid tumors may take more than 20 years to develop. Now more than ever lung cancer screening is critical as early diagnoses predict treatment success. A study comparing risk factor and model-based lung cancer screening in the FDNY WTC cohort found that several of the diagnosed lung cancers would have been missed if traditional guidelines were used for lung cancer screening [87]. The findings support the recent expansion by the United States Preventive Services Task Force (USPSTF) for CT lung cancer screening eligibility by lowering smoking history to $\geq 20$ pack-years and age 50 years old in this WTC occupational cohort [88]. As commonly known, dyspnea is a symptom with multiple origins-not only of a pulmonary etiology but also cardiovascular. A recent study demonstrated incident rates of FDNY WTC-exposed rescue/recovery workers with cardiovascular disease, such as myocardial infarction, stroke, unstable angina, coronary artery surgery or angioplasty, or cardiovascular disease-related death, were highest in those with the greatest WTC exposure intensity, even when adjusted for smoking status and age [89]. Given that there is a strong relationship between metabolic syndrome, a known risk factor for cardiovascular disease and WTC-LI; further studies are needed to explore the relationships between cardiovascular disease, respiratory disease, and WTC exposure.

Finally, the extensive longitudinal follow-up of the FDNY WTC exposure cohort will allow for a better understanding of risk factors for new and emerging conditions, such as the novel coronavirus disease 2019 (COVID-19). For example, a greater rate of $\mathrm{FEV}_{1}$ decline is associated with 
asthma and chronic obstructive pulmonary disease (COPD) in FDNY WTC rescue/recovery workers [90]. Recently, Weiden et al. found the same risk factors to be associated with severe COVID-19 disease (defined as hospitalization or death) in the currently active FDNY workforce (30\% of whom were WTC exposed) [91]. Further investigation of WTC-related health conditions as independent risk factors for severe COVID-19 are needed in WTC-exposed longitudinal cohorts.

\section{Conclusion}

In the days and months after 9/11, the FDNY reported the most common symptom in its workforce was cough, later termed "WTC cough syndrome" which was characterized with obstructive airways disease, GERD, and chronic rhinosinusitis. The most common pulmonary function abnormalities post-9/11 were accelerated decline in lung function and airways hyperreactivity. Causality to the WTC exposure was confirmed early on by demonstrating a dose-response relationship for many of these findings. Unlike other acute occupational exposures [34], the majority of FDNY WTCexposed rescue/recovery workers did not recover their lung function to pre-9/11 levels. Later it became clear that there was a subset of FDNY responders who had developed accelerated lung function decline for several years after 9/11. Several studies have identified important biomarkers related to WTC-lung injury, such as CRP, IgE, MMP-1, GMCSF, MDC, ApoAII, and ApoAI, while others have been found to be protective, such as MMP-12, MMP-3, GRO, and MCP-1 (Table 1). Although many of these biomarkers are not easily available in most laboratories, some may help predict the course of lung function and identify those who need closer monitoring and earlier intervention. Furthermore, these same studies suggest that metabolic syndrome is a unique risk factor and potential biomarker for WTC-LI and airway hyperreactivity which could be addressed clinically through lifestyle modifications such as that offered by the FIREHOUSE trial, a unique treatment approach to 9/11-related respiratory dysfunction. Studies have also demonstrated a relationship between systemic inflammatory conditions, such as sarcoidosis, with an increased incidence after $9 / 11$ and a unique disease phenotype involving not only pulmonary disease but also cardiac and bone/joint involvement. Obstructive sleep apnea has also been associated with WTC exposure with a dose-response relationship, similar to other WTC-related health conditions. Much of the treatment efforts of WTC-related lung disease have focused on those who remain symptomatic and have not recovered their lung function. Early intervention with ICS and ICS-LABA inhalers reduced the risk of prolonged symptoms such as dyspnea and escalated treatment approaches have been required for sarcoidosis using anti-TNF $\alpha$ agents.

Several of the WTC-related pulmonary disease findings suggest unique underlying inflammatory pathways that may explain the prolonged prevalence of these conditions even 20 years after 9/11. Early identification of those with 9/11-related inflammatory conditions could help detect those who need closer monitoring and earlier treatment. As demonstrated with 9/11-related cardiac sarcoidosis, prompt monitoring and intervention could prevent progression of potentially fatal disease. Finally, future research not only will focus on understanding these pathways but also on their interrelationships with co-morbidities, such as aging, cardiovascular disease, cancers, autoimmune diseases, PTSD, and even new emerging conditions like COVID-19. The longterm, ongoing study of this unique WTC-exposed cohort, beginning even before $9 / 11$, represents the first occupational study of its kind to provide quality longitudinal data similar to that of the original Framingham Heart Study $[92,93]$.

Funding The funded was provided by National Institute for Occupational Safety and Health (Grant Nos. 200-2017-93426 (World Trade Center Health Program Clinical Center of Excellence), 2002017-93326 (World Trade Center Health Program Data Center), U01-OH11300, U01-OH011855 and U01-OH012069) and National Heart, Lung, and Blood Institute (Grant No. R01HL119326).

\section{Declarations}

Conflict of interest The authors declare that they have no conflict of interest.

\section{References}

1. Lippmann M, Cohen MD, Chen LC (2015) Health effects of World Trade Center (WTC) dust: an unprecedented disaster's inadequate risk management. Crit Rev Toxicol 45(6):492-530

2. Lioy PJ, Weisel CP, Millette JR et al (2002) Characterization of the dust/smoke aerosol that settled east of the World Trade Center (WTC) in lower Manhattan after the collapse of the WTC 11 September 2001. Environ Health Perspect 110(7):703-714

3. McGee JK, Chen LC, Cohen MD et al (2003) Chemical analysis of World Trade Center fine particulate matter for use in toxicologic assessment. Environ Health Perspect 111(7):972-980

4. Heyder J, Svartengren M (2001) Basic principles of particle behavior in the human respiratory tract. CRC Press, Boca Raton

5. Yip J, Webber MP, Zeig-Owens R et al (2016) FDNY and 9/11: clinical services and health outcomes in World Trade Centerexposed firefighters and EMS workers from 2001 to 2016. Am J Ind Med 59(9):695-708

6. Centers for Disease Control and Prevention (2017) 9/11 World Trade Center health program History-Centers for disease control and prevention. https://www.cdc.gov/wtc/history.html. Accessed 1 Oct 2021 
7. Zadroga J (2011) 9/11 Health and Compensation Act of 2010 Pub. L. 111-347. Codified in Title XXXIII of the Public Health Service Act at 42 U.S.C. $\S \S 300 \mathrm{~mm}-300 \mathrm{~mm}-61,124$ Stat. 3623

8. Dasaro CR, Holden WL, Berman KD et al (2017) Cohort profile: World Trade Centr Health Program general responder cohort. Int J Epidemiol 46(2):e9

9. Reibman J, Liu M, Cheng Q et al (2009) Characteristics of a residential and working community with diverse exposure to World Trade Center dust, gas, and fumes. J Occup Environ Med 51(5):534-541

10. NYC 9/11 Health (2021) World Trade Center Health Registry. https://www1.nyc.gov/site/911health/about/wtc-health-registry. page. Accessed 1 Oct 2021

11. Yip J, Zeig-Owens R, Webber MP et al (2016) World Trade Center-related physical and mental health burden among New York City Fire Department emergency medical service workers. Occup Environ Med 73(1):13-20

12. Webber MP, Gustave J, Lee R et al (2009) Trends in respiratory symptoms of firefighters exposed to the world trade center disaster: 2001-2005. Environ Health Perspect 117(6):975-980

13. Niles JK, Webber MP, Liu X et al (2014) The upper respiratory pyramid: early factors and later treatment utilization in World Trade Center exposed firefighters. Am J Ind Med 57(8):857-865

14. Webber MP, Lee R, Soo J et al (2011) Prevalence and incidence of high risk for obstructive sleep apnea in World Trade Centerexposed rescue/recovery workers. Sleep Breath Schlaf Atmung 15(3):283-294

15. Glaser MS, Shah N, Webber MP et al (2014) Obstructive sleep apnea and World Trade Center exposure. J Occup Environ Med 56(Suppl 10):S30-34

16. Zeig-Owens R, Webber MP, Hall CB et al (2011) Early assessment of cancer outcomes in New York City firefighters after the 9/11 attacks: an observational cohort study. Lancet (London, England) 378(9794):898-905

17. Soo J, Webber MP, Gustave J et al (2011) Trends in probable PTSD in firefighters exposed to the World Trade Center disaster, 2001-2010. Disaster Med Public Health Prep 5(Suppl 2):S197-203

18. Niles JK, Webber MP, Gustave J et al (2011) Comorbid trends in World Trade Center cough syndrome and probable posttraumatic stress disorder in firefighters. Chest 140(5):1146-1154

19. Neria Y, DiGrande L, Adams BG (2011) Posttraumatic stress disorder following the September 11, 2001, terrorist attacks: a review of the literature among highly exposed populations. Am Psychol 66(6):429-446

20. Lowell A, Suarez-Jimenez B, Helpman L et al (2018) 9/11-related PTSD among highly exposed populations: a systematic review 15 years after the attack. Psychol Med 48(4):537-553

21. Liu B, Tarigan LH, Bromet EJ, Kim H (2014) World Trade Center disaster exposure-related probable posttraumatic stress disorder among responders and civilians: a meta-analysis. PLoS ONE 9(7):e101491

22. Berninger A, Webber MP, Cohen HW et al (2010) (2010) Trends of elevated PTSD risk in firefighters exposed to the World Trade Center disaster: 2001-2005. Public Health Rep (Washington, D.C.: 1974) 125(4):556-566

23. Centers for Disease Control and Prevention (2021) Program Statistics: Members with Certifications by Zadroga Act Categories of Conditions. https://www.cdc.gov/wtc/ataglance.html\#membe rZadroga. Accessed 1 Oct 2021

24. Prezant DJ (2008) World Trade Center cough syndrome and its treatment. Lung 186(Suppl 1):S94-102

25. Prezant DJ, Levin S, Kelly KJ, Aldrich TK (2008) Upper and lower respiratory diseases after occupational and environmental disasters. Mt Sinai J Med 75(2):89-100
26. Prezant DJ, Weiden M, Banauch GI et al (2002) Cough and bronchial responsiveness in firefighters at the World Trade Center site. N Engl J Med 347(11):806-815

27. Weiden MD, Ferrier N, Nolan A et al (2010) Obstructive airways disease with air trapping among firefighters exposed to World Trade Center dust. Chest 137(3):566-574

28. de la Hoz RE, Shapiro M, Nolan A, Celedón JC, Szeinuk J, Lucchini RG (2020) Association of low FVC spirometric pattern with WTC occupational exposures. Respir Med 170:106058

29. Wisnivesky JP, Teitelbaum SL, Todd AC et al (2011) Persistence of multiple illnesses in World Trade Center rescue and recovery workers: a cohort study. Lancet (London, England) 378(9794):888-897

30. Antao VC, Pallos LL, Graham SL et al (2019) 9/11 residential exposures: the impact of world trade center dust on respiratory outcomes of lower manhattan residents. Int J Environ Res Public Health 16(5):798

31. Reibman J, Lin S, Hwang SA et al (2005) The World Trade Center residents' respiratory health study: new-onset respiratory symptoms and pulmonary function. Environ Health Perspect 113(4):406-411

32. Banauch GI, Alleyne D, Sanchez R et al (2003) Persistent hyperreactivity and reactive airway dysfunction in firefighters at the World Trade Center. Am J Respir Crit Care Med 168(1):54-62

33. Banauch GI, Dhala A, Alleyne D et al (2005) Bronchial hyperreactivity and other inhalation lung injuries in rescue/recovery workers after the World Trade Center collapse. Crit Care Med 33(1 Suppl):S102-106

34. Lemiere C, Chaboillez S, Welman M, Maghni K (2010) Outcome of occupational asthma after removal from exposure: a follow-up study. Can Respir J 17(2):61-66

35. Aldrich TK, Weakley J, Dhar S et al (2016) Bronchial reactivity and lung function after world trade center exposure. Chest 150(6):1333-1340

36. Aldrich TK, Gustave J, Hall CB et al (2010) Lung function in rescue workers at the World Trade Center after 7 years. N Engl J Med 362(14):1263-1272

37. Vossbrinck M, Zeig-Owens R, Hall CB et al (2017) Post9/11/2001 lung function trajectories by sex and race in World Trade Center-exposed New York City emergency medical service workers. Occup Environ Med 74(3):200-203

38. Banauch GI, Brantly M, Izbicki G et al (2010) Accelerated spirometric decline in New York City firefighters with alpha(1)-antitrypsin deficiency. Chest 138(5):1116-1124

39. Zeig-Owens R, Singh A, Aldrich TK et al (2018) Blood leukocyte concentrations, FEV(1) decline, and airflow limitation. A 15-year longitudinal study of world trade center-exposed firefighters. Ann Am Thorac Soc 15(2):173-183

40. Weiden MD, Naveed B, Kwon S et al (2013) Cardiovascular biomarkers predict susceptibility to lung injury in World Trade Center dust-exposed firefighters. Eur Respir J 41(5):1023-1030

41. Nolan A, Naveed B, Comfort AL et al (2012) Inflammatory biomarkers predict airflow obstruction after exposure to World Trade Center dust. Chest 142(2):412-418

42. Nolan A, Kwon S, Cho SJ et al (2014) MMP-2 and TIMP-1 predict healing of WTC-lung injury in New York City firefighters. Respir Res 15(1):5

43. Cho SJ, Nolan A, Echevarria GC et al (2013) Chitotriosidase is a biomarker for the resistance to World Trade Center lung injury in New York City firefighters. J Clin Immunol 33(6):1134-1142

44. Kwon S, Weiden MD, Echevarria GC et al (2013) Early elevation of serum MMP-3 and MMP-12 predicts protection from World Trade Center-lung injury in New York City Firefighters: a nested case-control study. PLoS ONE 8(10):e76099 
45. Weiden MD, Singh A, Goldfarb DG et al (2021) Serum Th-2 cytokines and FEV(1) decline in WTC-exposed firefighters: a 19-year longitudinal study. Am J Ind Med 64:845

46. Kanneganti M, Kamba A, Mizoguchi E (2012) Role of chitotriosidase (chitinase 1) under normal and disease conditions. J Epithelial Biol Pharmacol 5:1-9

47. Trevaskis JL, Parkes DG, Roth JD (2010) Insights into amylinleptin synergy. Trends Endocrinol Metab 21(8):473-479

48. Naveed B, Weiden MD, Kwon S et al (2012) Metabolic syndrome biomarkers predict lung function impairment: a nested case-control study. Am J Respir Crit Care Med 185(4):392-399

49. Kwon S, Crowley G, Mikhail M et al (2019) Metabolic syndrome biomarkers of World Trade Center airway hyperreactivity: a 16-year prospective cohort study. Int J Environ Res Public Health 16(9): 1486

50. Kwon S, Crowley G, Caraher EJ et al (2019) Validation of predictive metabolic syndrome biomarkers of world trade center lung injury: a 16-year longitudinal study. Chest 156(3):486-496

51. Kwon S, Lee M, Crowley G et al (2021) Dynamic metabolic risk profiling of world trade center-lung disease: a longitudinal cohort study. Am J Respir Crit Care Med 204:1035

52. Tsukiji J, Cho SJ, Echevarria GC et al (2014) Lysophosphatidic acid and apolipoprotein A1 predict increased risk of developing World Trade Center-lung injury: a nested case-control study. Biomarkers 19(2):159-165

53. Caraher EJ, Kwon S, Haider SH et al (2017) Receptor for advanced glycation end-products and World Trade Center particulate induced lung function loss: a case-cohort study and murine model of acute particulate exposure. PLoS ONE 12(9): 0184331

54. Crowley G, Kwon S, Haider SH et al (2018) Metabolomics of World Trade Center-lung injury: a machine learning approach. BMJ Open Respir Res 5(1):e000274

55. Crowley G, Kwon S, Ostrofsky DF et al (2019) Assessing the protective metabolome using machine learning in world trade center particulate exposed firefighters at risk for lung injury. Sci Rep 9(1):11939

56. Crowley G, Kim J, Kwon S et al (2021) PEDF, a pleiotropic WTC-LI biomarker: machine learning biomarker identification and validation. PLoS Comput Biol 17(7):e1009144

57. Iannuzzi MC, Rybicki BA, Teirstein AS (2007) Sarcoidosis. N Engl J Med 357(21):2153-2165

58. Webber MP, Yip J, Zeig-Owens R et al (2017) Post-9/11 sarcoidosis in WTC-exposed firefighters and emergency medical service workers. Respir Med 132:232-237

59. Izbicki G, Chavko R, Banauch GI et al (2007) World Trade Center "sarcoid-like" granulomatous pulmonary disease in New York City Fire Department rescue workers. Chest 131(5):1414-1423

60. Hena KM, Murphy S, Zhang Y, Shao Y, Kazeros A, Reibman J (2019) Clinical evaluation of sarcoidosis in community members with World Trade Center dust exposure. Int J Environ Res Public Health 16(7):1291

61. Crowley LE, Herbert R, Moline JM et al (2011) "Sarcoid like" granulomatous pulmonary disease in World Trade Center disaster responders. Am J Ind Med 54(3):175-184

62. Sunil VR, Radbel J, Hussain S et al (2019) Sarcoid-like granulomatous disease: pathologic case series in World Trade Center dust exposed rescue and recovery workers. Int J Environ Res Public Health 16(5):815

63. Hena KM, Yip J, Jaber $\mathrm{N}$ et al (2018) Clinical course of sarcoidosis in World Trade Center-exposed firefighters. Chest 153(1):114-123

64. Girvin F, Zeig-Owens R, Gupta D et al (2016) Radiologic features of World Trade Center-related sarcoidosis in exposed NYC fire department rescue workers. J Thorac Imaging 31(5):296-303
65. Cleven KL, Ye K, Zeig-Owens R et al (2019) Genetic variants associated with FDNY WTC-related sarcoidosis. Int J Environ Res Public Health 16(10):1830

66. Hill MR, Papafili A, Booth H et al (2006) Functional prostaglandin-endoperoxide synthase 2 polymorphism predicts poor outcome in sarcoidosis. Am J Respir Crit Care Med 174(8):915-922

67. Ahuja S, Zhu Z, Shao Y, Berger KI, Reibman J, Ahmed O (2018) Obstructive sleep apnea in community members exposed to World Trade Center dust and fumes. J Clin Sleep Med JCSM 14(5):735-743

68. Netzer NC, Stoohs RA, Netzer CM, Clark K, Strohl KP (1999) Using the Berlin Questionnaire to identify patients at risk for the sleep apnea syndrome. Ann Intern Med 131(7):485-491

69. Unnikrishnan D, Jun J, Polotsky V (2015) Inflammation in sleep apnea: an update. Rev Endocr Metab Disord 16(1):25-34

70. Bachert C, Vignola AM, Gevaert P, Leynaert B, Van Cauwenberge P, Bousquet J (2004) Allergic rhinitis, rhinosinusitis, and asthma: one airway disease. Immunol Allergy Clin North Am 24(1):19-43

71. Irwin RS, French CL, Chang AB, Altman KW (2018) Classification of cough as a symptom in adults and management algorithms: CHEST guideline and expert panel report. Chest 153(1):196-209

72. Irwin RS, French CT, Lewis SZ, Diekemper RL, Gold PM (2014) Overview of the management of cough: CHEST guideline and expert panel report. Chest 146(4):885-889

73. Putman B, Lahousse L, Singh A et al (2020) Dyspnea and inhaled corticosteroid and long-acting $\beta$-agonist therapy in an occupational cohort: a longitudinal study. Ann Am Thorac Soc 17(6):770-773

74. Goldfarb DG, Putman B, Lahousse L et al (2021) Lung function decline before and after treatment of World Trade Center associated obstructive airways disease with inhaled corticosteroids and long-acting beta agonists. Am J Ind Med 64:853

75. Loupasakis K, Berman J, Jaber N et al (2015) Refractory sarcoid arthritis in World Trade Center-exposed New York City firefighters: a case series. J Clin Rheumatol 21(1):19-23

76. Sweiss NJ, Patterson K, Sawaqed R et al (2010) Rheumatologic manifestations of sarcoidosis. Semin Respir Crit Care Med 31(4):463-473

77. Identifier: NCT03581006 (2018) Food Intake REstriction for Health OUtcome Support and Education (FIREHOUSE) Trial. http://www.ClinicalTrials.gov

78. Kwon S, Riggs J, Crowley G et al (2020) Food intake restriction for health outcome support and education (FIREHOUSE) protocol: a randomized clinical trial. Int J Environ Res Public Health 17(18):6569

79. Young ILR, Kwon S et al (2021) food intake restriction for health outcome support and education (FIREHOUSE): a randomized clinical trial. Am J Respir Crit Care Med 203:A3069

80. Riggs JLR, Kwon S et al (2019) Food intake restriction for health outcome support and education (FIREHOUSE) Trial: study design. Chest 155:227A

81. Sevick MA, Woolf K, Mattoo A et al (2018) The Healthy Hearts and Kidneys (HHK) study: design of a $2 \times 2$ RCT of technologysupported self-monitoring and social cognitive theory-based counseling to engage overweight people with diabetes and chronic kidney disease in multiple lifestyle changes. Contemp Clin Trials 64:265-273

82. Li J, Cone JE, Brackbill RM, Giesinger I, Yung J, Farfel MR (2019) Pulmonary fibrosis among World Trade Center responders: results from the WTC Health Registry Cohort. Int J Environ Res Public Health 16(5):825

83. Li J, Brackbill RM, Liao TS et al (2016) Ten-year cancer incidence in rescue/recovery workers and civilians exposed to the September 11, 2001 terrorist attacks on the World Trade Center. Am J Ind Med 59(9):709-721 
84. Shapiro MZ, Wallenstein SR, Dasaro CR et al (2020) Cancer in general responders participating in World Trade Center Health Programs, 2003-2013. JNCI Cancer Spectr 4(1):pkz090

85. Solan S, Wallenstein S, Shapiro M et al (2013) Cancer incidence in world trade center rescue and recovery workers, 2001-2008. Environ Health Perspect 121(6):699-704

86. Li J, Yung J, Qiao B et al (2021) Cancer incidence and risk in a combined cohort of World Trade Center rescue and recovery workers, 2002-2015. J Natl Cancer Inst. https://doi.org/10.1093/ jnci/djab165

87. Cleven KL, Vaeth B, Zeig-Owens R et al (2021) Performance of risk factor-based guidelines and model-based chest CT lung cancer screening in world trade center-exposed fire department rescue/recovery workers. Chest 159(5):2060-2071

88. Krist AH, Davidson KW, Mangione CM et al (2021) Screening for lung cancer: US preventive services task force recommendation statement. JAMA 325(10):962-970

89. Cohen HW, Zeig-Owens R, Joe C et al (2019) Long-term cardiovascular disease risk among firefighters after the world trade center disaster. JAMA Netw Open 2(9):e199775

90. Singh A, Liu C, Putman B et al (2018) Predictors of asthma/ COPD overlap in FDNY firefighters with world trade center dust exposure: a Longitudinal Study. Chest 154(6):1301-1310
91. Weiden MD, Zeig-Owens R, Singh A et al (2021) Pre-COVID-19 lung function and other risk factors for severe COVID-19 in first responders. ERJ Open Res 7(1):00610-02020

92. Mahmood SS, Levy D, Vasan RS, Wang TJ (2014) The Framingham Heart Study and the epidemiology of cardiovascular disease: a historical perspective. Lancet (London, England) 383(9921):999-1008

93. Tsao CW, Vasan RS (2015) Cohort profile: the Framingham Heart Study (FHS): overview of milestones in cardiovascular epidemiology. Int J Epidemiol 44(6):1800-1813

94. Zeig-Owens R, Singh A, Aldrich TK et al (2018) blood leukocyte concentrations, FEV1 decline, and airflow limitation. A 15-year longitudinal study of world trade center-exposed firefighters. Ann Am Thorac Soc 15(2):173-183

95. Weiden MD, Singh A, Goldfarb DG et al (2021) Serum Th-2 cytokines and FEV1 decline in WTC-exposed firefighters: a 19-year longitudinal study. Am J Ind Med 64:845

Publisher's Note Springer Nature remains neutral with regard to jurisdictional claims in published maps and institutional affiliations. 